\section{Correlation between microaneurysm closure rate and reduction in macular thickness following laser photocoagulation of diabetic macular edema}

N Sachdev, V Gupta, V Abhiramamurthy, R Singh and A Gupta not correlate with the initial closure rate at 2 weeks $(r=-0.039, P=0.413)$.

Conclusion Following laser photocoagulation for CSME, an OCT at 2 weeks is more informative and better correlates with the final outcome than an FFA at 2 weeks.

Eye (2008) 22, 975-977; doi:10.1038/sj.eye.6702801; published online 6 April 2007

Keywords: CSME; laser photocoagulation; microaneurysms; retinal thickness

\section{Introduction}

The standard of care for treatment of clinically significant macular oedema (CSME) is focal laser photocoagulation. ${ }^{1}$ The response of CSME to laser treatment is characterized by closure of leaking microaneurysms, best visualized on fundus fluorescein angiogram (FFA), ${ }^{2}$ and reduction in macular thickness, best measured on optical coherence tomography (OCT). ${ }^{3}$ It seems obvious that as the microaneurysms close after the effect of laser photocoagulation, there will be cessation of leakage and hence a reduction in macular thickness will occur. However, correlation between the above two entities, that is the extent of microaneurysmal closure achieved and the resultant reduction in macular thickness, has not been studied before.

Materials and methods

This prospective study, approved by the ethics committee of our institute, included 50 patients
Department of Ophthalmology, Post Graduate Institute of Medical Education and Research, Chandigarh, India

Correspondence: A Gupta, Department of Ophthalmology, Post Graduate Institute of Medical Education and Research, Sector 12, Chandigarh 160012, India

Tel/fax: + 910172

2747837.

E-mail: eyepgi@sify.com

Received: 19 September 2006

Accepted in revised form: 28 February 2007 Published online: 6 April 2007 
(50 eyes) of type II diabetes mellitus having nonproliferative diabetic retinopathy with CSME in at least one eye. Baseline retinal thickness (mean of two readings) was measured in posterior central $6 \mathrm{~mm}$ of retina in nine predetermined quadrants using a fast macular thickness scan on STRATUS OCT. An angiogram was also performed and the dye transit phase picture was modified using the Adobe Photoshop software ${ }^{\circledR}$ and Coral graphics ${ }^{\mathbb{R}}$ to superimpose an OCT-like grid, created by assuming that the approximate distance between the major vascular arcades in the centre of posterior pole is around $6 \mathrm{~mm}$. The grid was centred on the foveal centre and the number of leaking microaneurysms (those which became fuzzy in the late phase of angiogram) was counted.

Subsequently, the patients underwent standard focal or grid photocoagulation as described by ETDRS ${ }^{1}$ using frequency-doubled Nd:YAG $532 \mathrm{~nm}$ laser. Repeat OCT and FFA were performed at 2 and 12 weeks following laser photocoagulation to measure the change in retinal thickness and the number of leaking microaneurysms with respect to the baseline. All microaneurysm counts were performed by two investigators separately, who were blinded to the patient protocol, and a mean of the two readings was taken. Statistical analysis was performed using paired- $t$ test and Pearson's correlation test.

\section{Results}

OCT at 2 weeks, showed a significant reduction in retinal thickness in the central $1 \mathrm{~mm}$ quadrant $(P=0.0004)$, whereas at 12 weeks the reduction was significant in all the nine quadrants $(P<0.0001)$

(Table 1). However, the average retinal thickness in the posterior $6 \mathrm{~mm}$ retina showed a significant reduction at both $2(P=0.02)$ and 12 weeks $(P<0.0001)$. On FFA, the closure rate of pre-existing leaking microaneurysms at 2 weeks was only $0.67 \%$. However, a majority of these microaneurysms $(89.1 \%)$ were observed to close by 12 weeks (Table 1). The change in retinal thickness correlated significantly with the decrease in the number of leaking microaneurysms at 12 weeks $(r=0.597, P<0.0001)$, but not at 2 weeks $(r=-0.228, P=0.112)$.

On OCT, the final reduction in retinal thickness achieved at 12 weeks from baseline significantly correlated with the initial decrease in retinal thickness at 2 weeks $(r=0.66, P<0.0001)$. This correlation was even better observed for the central $1 \mathrm{~mm}$ quadrant $(r=0.72$, $P<0.0001$ ) (Table 2). However, on FFA, the final closure rate of leaking microaneurysms at 12 weeks from baseline did not correlate with the initial closure rate at 2 weeks $(r=0.039, P=0.413)$.

Table 1 Distribution of mean retinal thickness $(\mu \mathrm{m})$ and number of leaking microaneurysms at baseline and at each follow-up visit following laser photocoagulation

\begin{tabular}{|c|c|c|c|c|c|c|}
\hline Quadrants & $\begin{array}{l}\text { Baseline mean } \\
\text { retinal thickness } \\
\quad( \pm S D)\end{array}$ & $\begin{array}{c}\text { Mean retinal } \\
\text { thickness at } 2 \\
\text { weeks }( \pm S D)\end{array}$ & $\begin{array}{c}\text { Mean retinal } \\
\text { thickness at } 12 \\
\text { weeks }( \pm S D)\end{array}$ & $\begin{array}{c}\text { Average number } \\
\text { of leaking } \\
\text { MAS at } \\
\text { baseline (range) }\end{array}$ & $\begin{array}{c}\text { Average number } \\
\text { of leaking } \\
\text { MAS at } \\
2 \text { weeks (range) }\end{array}$ & $\begin{array}{c}\text { Average number } \\
\text { of leaking } \\
\text { MAS at } \\
12 \text { weeks (range }\end{array}$ \\
\hline Central quadrant & $306.7 \pm 54.8$ & $291.0 \pm 44.9$ & $251.0 \pm 36.3$ & $3.02(1-4)$ & $2.78(1-4)$ & $1.52(0-3)$ \\
\hline Inferior inner quadrant & $295.5 \pm 41.7$ & $291.5 \pm 41.7$ & $258.5 \pm 35.7$ & $11.96(5-32)$ & $11.84(5-32)$ & $2.34(0-9)$ \\
\hline Inferior outer quadrant & $307.8 \pm 54.2$ & $302.4 \pm 49.4$ & $268.6 \pm 46.4$ & $16.34(5-39)$ & $16.34(5-39)$ & $.66(0-6)$ \\
\hline Nasal inner quadrant & $294.7 \pm 45.5$ & $291.3 \pm 39.6$ & $259.8 \pm 34.8$ & $11.72(2-27)$ & $11.6(2-27)$ & $2.10(0-14)$ \\
\hline Nasal outer quadrant & $318.0 \pm 57.7$ & $317.1 \pm 52.3$ & $279.6 \pm 46.1$ & $16.02(2-29)$ & $15.90(2-29)$ & $1.86(0-13)$ \\
\hline Superior inner quadrant & $299.6 \pm 52.3$ & $295.9 \pm 44.6$ & $262.7 \pm 43.7$ & $13.06(2-34)$ & $12.92(2-34)$ & $.82(0-5)$ \\
\hline Superior outer quadrant & $278.5 \pm 41.1$ & $283.5 \pm 39.9$ & $253.7 \pm 37.4$ & $11.74(1-45)$ & $11.74(1-45)$ & $.90(0-12)$ \\
\hline Temporal inner quadrant & $292.9 \pm 46.6$ & $287.3 \pm 41.1$ & $256.4 \pm 43.6$ & $13.58(2-40)$ & $13.58(2-40)$ & $.82(0-9)$ \\
\hline Temporal outer quadrant & $284.8 \pm 49.7$ & $293.5 \pm 52.1$ & $250.9 \pm 41.2$ & $12.86(3-35)$ & $12.86(3-35)$ & $0.42(0-7)$ \\
\hline Posterior $6 \mathrm{~mm}$ retina & $297.6 \pm 28.6$ & $292.2 \pm 25.2$ & $260.4 \pm 21.3$ & $110.3(58-197)$ & $109.56(58-197)$ & $11.44(3-33)$ \\
\hline
\end{tabular}

Table 2 Correlation of change in retinal thickness $(\mu \mathrm{m})$ in central $1 \mathrm{~mm}$ quadrant at 2 and 12 weeks following laser photocoagulation

\begin{tabular}{|c|c|c|c|}
\hline SI.No. & $\begin{array}{l}\text { Change in retinal thickness at } 2 \\
\text { weeks compared to baseline }\end{array}$ & No. of eyes & $\begin{array}{l}\text { Corresponding change in retinal } \\
\text { thickness at } 12 \text { weeks compared } \\
\text { to baseline }\end{array}$ \\
\hline 1 & Increase by $>10 \mu \mathrm{m}$ & 8 & Decrease by $29.1 \pm 10.9 \mu \mathrm{m}^{*}$ \\
\hline 2 & No change $( \pm 10 \mu \mathrm{m})$ & 12 & Decrease by $36.7 \pm 21.3 \mu \mathrm{m}^{*}$ \\
\hline 3 & Decrease by $10-40 \mu \mathrm{m}$ & 19 & Decrease by $63.0 \pm 21.7 \mu \mathrm{m}^{*}$ \\
\hline 4 & Decrease by $>40 \mu \mathrm{m}$ & 11 & Decrease by $85.0 \pm 40.1 \mu \mathrm{m}^{*}$ \\
\hline
\end{tabular}




\section{Discussion}

We observed a significant reduction in retinal thickness at both 2 and 12 weeks following laser photocoagulation, whereas majority of microaneurysms were observed to close by 12 weeks only. How, can reduction in thickness be achieved without microaneurysm closure, remains the question. This probably could be explained by the fact, that after laser photocoagulation, individual microaneurysms may show some reduction in leakage at an earlier stage, a fact that may be very difficult to appreciate even on FFA, whereas their complete closure takes a longer time. ${ }^{2}$ This delayed closure of microaneurysms is possibly mediated by proliferation of new and functionally better pigmented epithelial cells and endothelial cells leading to a more efficient blood retinal barrier. ${ }^{2}$ Hence, expectedly, a significant correlation between the above two entities was seen only at 12 weeks and not at 2 weeks.

A significantly positive correlation between final reduction in retinal thickness on OCT at 12 weeks with initial improvement at 2 weeks, especially in the central $1 \mathrm{~mm}$ quadrant, suggest that the eyes which show a good initial response on OCT at 2 weeks continue to do better even at 12 weeks compared to those eyes with comparatively poorer initial response. However, similar interpretation could not be obtained from FFA. Hence we suggest that since an OCT at 2 weeks is more informative than FFA at 2 weeks, it should be regularly performed after laser photocoagulation.

\section{References}

1 Early Treatment Diabetic Retinopathy Study Research Group. Photocoagulation for diabetic macular edema. Early Treatment Diabetic Retinopathy Study report number 1. Arch Ophthalmol 1985; 103: 1796-1806.

2 Gogi D, Gupta A, Gupta V, Pandav SS, Dogra MR. Retinal microaneurysmal closure following focal laser photocoagulation in diabetic macular edema. Ophthalmic Surg Lasers 2002; 33: 362-367.

3 Rivellese M, George A, Sulkes D, Reichel E, Puliafito C. Optical coherence tomography after laser photocoagulation for clinically significant macular edema. Ophthalmic Surg Lasers 2000; 31: 192-197.

Supplementary Information accompanies the paper on the Eye website (http://www.nature.com/eye) 